\title{
A interpretação e a tradução de/para línguas de sinais: contextos de serviços públicos e suas demandas
}

\author{
Carlos Henrique Rodrigues, Silvana Aguiar dos Santos*
}

\section{Introdução}

Atualmente, é possível afirmar que os campos de atuação dos intérpretes e dos tradutores de língua de sinais têm se ampliado significativamente. Cada vez mais, a interpretação e a tradução de/para a línguas de sinais têm sido demandadas, principalmente em ambientes acadêmicos. Entretanto, ainda carecemos de pesquisas capazes de apresentar os diversos contextos sociais em que elas acontecem, assim como de refletir sobre as características dessas atividades em decorrência dos espaços que as abrigam.

É importante destacar que o contexto situacional em que a tradução e a interpretação ocorrem é, inclusive, um de seus aspectos distintivos, já que o intérprete realiza seu trabalho na presença de seu público e o tradutor não necessariamente (Cavallo, Reuillard, 2016). Uma análise dos cenários em que essas atividades são desenvolvidas mostra que, enquanto a interpretação é totalmente dependente da situação imediata e das circunstâncias em que se

\footnotetext{
* Carlos Henrique Rodrigues é doutor em Linguística Aplicada e professor do Departamento de Língua de Sinais Brasileira da Universidade Federal de Santa Catarina; Silvana Aguiar dos Santos é doutora em Estudos da Tradução pela Universidade Federal de Santa Catarina e professora do Departamento de Língua de Sinais Brasileira da UFSC.
} 
efetivam a produção do texto fonte e do alvo, a tradução pode ser realizada fora do contexto a que se destina, já que o texto fonte está pronto e o público terá acesso ao texto alvo após sua conclusão. Portanto, o processo tradutório confere ao profissional a possibilidade de realizar o seu trabalho no ambiente que preferir, pois, como mencionamos acima, a tradução não demanda necessariamente a participação presencial e imediata do público.

Por outro lado, ao colocar em contato direto o profissional e o público, a interpretação caracteriza-se pela diversidade de ambientes em que essa relação ocorre: contextos educacionais, políticos, religiosos, jurídicos, familiares, etc. Vale mencionar que esses espaços vão desde contextos intrassociais até contextos internacionais (Pöchhacker, 2004). Além disso, a interpretação pode assumir diferentes perspectivas interacionais, visto que pode ser um processo monológico, mais característico de contextos de conferência, ou dialógico, comum aos contextos comunitários.

\section{A interpretação e a tradução de/para línguas de sinais}

Neste texto, consideramos a interpretação e a tradução como dois lados justapostos da mesma moeda. Assim, ainda que o termo "tradução" seja empregado por alguns como um hiperônimo para se referir indistintamente a ambas as atividades, reconhecemos que elas possuem diferenças significativas. Os conhecimentos e habilidades requeridos para a execução de cada uma delas, assim como o modo por meio do qual se realizam, são distintos. Uma aproximação inicial permite afirmar que a tradução se vincula basicamente à manipulação de "textos escritos" (i.e. acabados e registrados em um dado suporte) e a interpretação à manipulação de "textos orais" (i.e. em processo de produção e, por sua vez, não registrados) (Gile, 1998, 2004; Pagura, 2003, 2015). Entretanto, é importante que se considere uma breve caracterização capaz de nos oferecer uma melhor distinção entre tradução e interpretação.

Portanto, (a) na tradução, ao ter como matéria-prima o texto pronto e disponível em dado suporte, o profissional pode trabalhar sem contato direto com o público e, portanto, o resultado de seu trabalho, devidamente revisto e 
refinado, será automaticamente registrado com o objetivo de durar. Essas condições de produção permitem que o profissional tenha, na maioria dos casos, liberdade para imprimir seu próprio ritmo ao trabalho e para escolher o ambiente em que pretende executá-lo; e (b) na interpretação, ao ter como matéria-prima o discurso em fluxo, o profissional trabalha, na maioria dos casos, em contato direto e imediato com o autor do texto e com o público e, portanto, o resultado de seu trabalho vai sendo conhecido à medida que desaparece, visto não possuir registro automático ${ }^{1}$. Essas condições de produção impõem ao profissional o ritmo do autor do discurso e uma dependência contextual mais explícita e direta que na tradução, já que ele precisa estabelecer contato com sua audiência.

Nas definições acima, observamos alguns aspectos diferenciadores da tradução e da interpretação: (i) o caráter do texto fonte: concluído e registrado versus em fluxo e transitório; (ii) a condição de trabalho: menos dependente do contexto e sem a obrigatoriedade de contato com o público versus totalmente dependente do contexto e com a necessidade de contato com o público; e (iii) o registro do produto: automático e duradouro versus não automático e efêmero.

É importante mencionar que esses aspectos se desdobram em alguns outros, os quais também contribuem com a diferenciação entre a tradução e a interpretação: as competências e habilidades linguísticas requeridas do profissional; o tipo de apoio externo e interno que pode ser utilizado; a tecnologia que pode ser empregada; a possibilidade de revisão etc. Além disso, ao envolver uma língua de sinais, os processos tradutórios e interpretativos, além de serem interlinguísticos, tornam-se também intermodais (Padden, 2000; Rodrigues, 2013).

Os processos intermodais caracterizam-se por envolver línguas de diferentes modalidades: uma vocal-auditiva e outra gestual-visual. $\mathrm{O}$ fato de

\footnotetext{
1 O termo "automático" refere-se ao fato de que não há como produzir a tradução sem seu registro. O registro automático é condição sine qua non da tradução, pois é uma decorrência esperada e necessária desse processo. Já na interpretação o registro não é automático, ainda que possa ser realizado, pois a interpretação não demanda nenhum tipo de registro, já que ele não é uma decorrência esperada nem necessária ao processo.
} 
uma das línguas ser gestual-visual impacta significativamente o processo, já que as línguas de sinais, articuladas externamente ao corpo, exploram mais a simultaneidade na constituição dos sinais e sentenças; não são dependentes de preposições, conjunções e artigos; possuem relações sintáticas constituídas espacialmente; etc. (Klima \& Bellugi, 1979; Brito, 1995; Meier, 2004; Quadros \& Karnopp, 2004).

Com a distinção entre os dois processos, é possível observar que a interpretação intermodal é uma atividade mais comum e frequente que a tradução intermodal (Wurm, 2010; Rodrigues \& Beer, 2015). Diversos são os fatores responsáveis por essa preponderância da interpretação sobre a tradução. O principal parece ser a ausência de um sistema consolidado de escrita de língua de sinais com ampla circulação social. Esse aspecto pode ser visto como um dos efeitos da modalidade de língua sobre a tradução/interpretação.

Os processos tradutórios entre duas línguas orais, ainda que envolvam a língua em uso $^{2}$, podem valer-se do apoio da escrita como sistema estabelecido e de uso corrente. Todavia, alguns processos tradutórios intermodais não têm como matéria-prima a escrita e, muitas vezes, não podem se valer dela, já que as escritas de línguas de sinais, como mencionado acima, estão em vias de consolidação.

Assim, para além da tradução que envolve um sistema de escrita de línguas de sinais, temos aquela tradução que não envolve a escrita, mas sim o registro em vídeo ou, em alguns casos, quando o texto final é em língua oral, o registro em áudio. Segundo Wurm (2010, p.20, tradução nossa), “devido à possibilidade de se trabalhar com TFs [textos fonte] registrados e de se gravar e regravar os TAs [textos alvo] com tempo potencialmente ilimitado e sem os

\footnotetext{
${ }^{2}$ Algumas traduções entre línguas orais estão relacionadas ao registro da língua em sua produção oral como ocorre com processos de dublagem e voice-over. Além disso, podemos pensar na tradução oral à prima vista (Sight translation) ou interpretação à prima vista (Sight interpreting), as quais envolvem a "leitura" imediata de um texto escrito numa língua por meio de outra, ou seja, parte da linguagem escrita (texto fonte) tendo como objetivo a linguagem oral (texto alvo).
} 
participantes primários, a noção de tradução de língua de sinais vem ganhando destaque" ${ }^{\prime 3}$.

De maneira geral, é possível considerar, portanto, que a tradução intermodal, envolvendo somente a escrita ou o registro em vídeo, e a interpretação intermodal são distintas e possuem funções e inserções sociais diferenciadas.

\section{Contextos de caráter intrassocial e internacional.}

No que se refere à atividade interpretativa, é comum observarmos o agrupamento dos múltiplos e diversificados contextos nos quais ela ocorre em dois grandes guarda-chuvas: (1) community interpreting, em português "interpretação comunitária", e (2) conference interpreting, em português "interpretação de conferência".

Com base em Wadensjö (1998) e em Gile (1998), Rodrigues (2010) apresenta um quadro comparativo entre a interpretação comunitária e a de conferência. Podemos depreender, com base em suas reflexões, que a interpretação de conferências é aquela realizada diante do grande público de forma basicamente monológica. Os eventos que envolvem mais de uma língua, os programas veiculados na mídia, ou ainda alguns encontros e reuniões contam muitas vezes com a presença e atuação de intérpretes de conferência que têm pouca demanda de viabilização de diálogos entre os participantes.

A interpretação comunitária, por sua vez, é aquela que "ocorre na esfera pública, com o intuito de facilitar a comunicação dos não falantes da língua oficial do país, e o seu consequente acesso aos provedores de serviços, tais como a educação, a saúde e os contextos legais" (Rodrigues, 2010, p.05). Nesses contextos, a atuação principal tem caráter dialógico, já que o profissional realiza certa mediação social em interações face a face de falantes de distintas línguas. Além disso, muitos profissionais não só viabilizam a

\footnotetext{
3 " [...] due to the ability to work with fixed STs and record and re-record TTs with potentially unrestricted time and in the absence of the primary participants, the notion of sign language translation is gaining prominence".
} 
interação, mas se envolvem com a defesa de direitos, com o apoio às minorias, às comunidades estrangeiras, assim como com a militância em prol do reconhecimento, da aceitação e do respeito à diversidade linguística e cultural.

Considerando a diversidade de demandas de caráter intrassocial e internacional, os profissionais tradutores e intérpretes de línguas de sinais atuam em diferentes contextos sociais. Um panorama desses contextos é apresentado por Rodrigues (2010, p. 4,5, grifos do autor):

[...] Contextos Educacionais - em todos os níveis de ensino, inclusive em vestibulares, concursos e outros; Contextos clínicos e hospitalares acompanhando não somente as consultas médicas, mas exames, cirurgias, tratamentos médicos, psiquiátricos e psicológicos etc; Contextos legais - em audiências, julgamentos, juizados, delegacias, conciliações, consulta a advogados, ministério público, casamentos etc; Contextos Familiares conversas de pais com filhos, irmãos, parentes, namorados, amigos, assuntos íntimos, confidenciais, etc; Contextos Midiáticos - telejornais, programas políticos, filmes, documentários, sites e outros produtos da mídia; Contextos Religiosos - nos mais diversos tipos de atividades vinculadas a grupos religiosos: cultos, missas, reuniões etc; Contextos de Lazer e Turismo parques, clubes, museus, passeios, excursões, etc; Contextos de Conferências grandes eventos, inclusive de caráter acadêmico e internacional. [...] Contextos empresariais - em treinamentos, seleções, reuniões e, até mesmo, no dia a dia da empresa; os Contextos de serviços públicos/ sociais - acompanhamentos em serviços sociais para cadastramento, atendimentos e retirada de benefícios; dentre outros.

Os contextos apresentados por Rodrigues (2010) nos permitem perceber que os tradutores e intérpretes de língua de sinais possuem um campo de atuação profissional bem amplo e diversificado que envolve bem mais que contextos de interpretação que podem ser classificados como comunitários ou de conferência. Por diversas vezes, o campo de atuação dos profissionais tradutores e intérpretes ultrapassam esses âmbitos, como ocorre com a interpretação religiosa e a interpretação de ligação ou acompanhamento, por exemplo, as quais perpassam distintos contextos, situações e ambientes. 


\section{A tradução e a interpretação em alguns contextos de serviços públicos}

O Decreto 5.626/2005 estabelece o direito das pessoas surdas ou com deficiência auditiva aos serviços públicos de educação e saúde por meio, por exemplo, de profissionais capacitados para o uso de Libras ou de profissionais aptos à tradução e interpretação. Entretanto, não menciona outros contextos de serviços públicos, tais como os jurídicos.

É importante destacar que, ao contrário do que muitos pensam, nos serviços públicos não há espaço somente para a interpretação. Embora a interpretação comunitária se destaque neles, encontramos demandas por serviços de tradução. Isso se deve ao fato de possuirmos, dentre outros, diversos materiais que circulam em ambientes educacionais, em serviços jurídicos e de saúde, por exemplo, que são destinados ao público em geral e que podem ou precisam estar em outras línguas.

A tradução e a interpretação em serviços públicos vêm sendo problematizadas e discutidas por diferentes autores em âmbito internacional. Contudo, as discussões no contexto brasileiro ainda são incipientes. Considerando essa lacuna, apresentaremos uma breve reflexão sobre a tradução e a interpretação de/para línguas de sinais em três contextos de serviços públicos.

\subsection{Contextos de educação}

Os contextos educacionais podem ser definidos como (i) espaços em que o educar se realiza; (ii) todo e qualquer ambiente em que a prática educativa está presente; (iii) lugares que abrigam atividades e ações educacionais; e (iv) circunstâncias que envolvem os processos de ensino e de aprendizagem. Nessa perspectiva, é possível visualizar a multiplicidade dos contextos educacionais, visto que envolvem a educação como processo de humanização, socialização e formação pessoal e profissional.

É importante mencionar que os profissionais envolvidos, direta ou indiretamente, com a educação compreendem o termo "educação" de maneira distinta. Essa diversidade de entendimentos decorre da complexidade e 
multidimensionalidade do fenômeno educativo, visto que "a investigação de sua natureza, de suas especificidades e de suas funções pode ser feita sob vários enfoques: o antropológico, o sociológico, o econômico, o psicológico, o biológico, o histórico e o pedagógico" (Libâneo, 2007, p.69).

Devido à sua relevância, os contextos educacionais são foco de diversas pesquisas, estudos e produções. Diante de tantas abordagens e visões sobre esses ambientes, é importante que os tradutores e intérpretes, que trabalham ou atendem esses espaços, os conheçam bem e reflitam sobre sua presença e atuação neles. Atualmente, alguns autores têm categorizado a educação como: formal, não formal e informal (Ghon, 2006; Libâneo, 2007). De maneira simples, é possível entender que os contextos de educação formal são aqueles em que a educação é organizada, sistemática, estruturada e intencionalmente planejada, possuindo uma ordem sequencial e disciplinar, tais como escolas, universidades e demais instituições de formação profissional.

Por outro lado, os contextos em que se dá a educação não formal, são aqueles em que a educação, embora com caráter de intencionalidade, possui baixo grau de estruturação e sistematização, com relações pedagógicas não formalizadas. Esses contextos promovem o compartilhar de conhecimentos e experiências por meio de interações coletivas visando, muitas vezes, à construção da cidadania: movimentos sociais, trabalhos comunitários, atividades culturais, meios de comunicação, dentre outros.

Já os contextos em que a educação informal se encontra são aqueles que abrigam processos sociais de construção e compartilhamento de valores, conhecimentos e costumes de forma não intencional nem institucionalizada, como ocorre nos espaços comuns do dia a dia: família, trabalho, locais de lazer, etc. Nesses ambientes, compartilham-se as experiências vividas e os resultados se mostram espontaneamente nos modos de ser, agir e pensar das pessoas (Ghon, 2006; Libâneo, 2007).

Partindo-se dessa categorização básica, torna-se evidente que a atuação no campo da educação exige do intérprete um conjunto de conhecimento e saberes didáticos e pedagógicos específicos (Rodrigues \& Silvério, 2011), os 
quais serão a base orientadora das escolhas e tomadas de decisão demandadas pelos processos tradutórios e interpretativos que ocorrem na ou visam à educação formal, não formal e informal.

O profissional que atua em espaços educacionais formais tem sido comumente chamado de intérprete educacional. Ao abordar contextos de educação formal, Albres (2015, p. 39) apresenta algumas denominações utilizadas para se referir ao profissional que atua na educação: professor intérprete da Língua Brasileira de Sinais/Língua Portuguesa; professor intérprete das linguagens e códigos aplicáveis; professor-intérprete; intérprete educacional; intérprete especialista para atuar na área da educação; intérprete tutor e tradutor/intérprete escolar. Ao analisar esse conjunto de denominações dadas aos profissionais intérpretes, Albres (2015, p. 41) afirma que a denominação que vem sendo aceita e empregada por pesquisadores da área é de fato a de intérprete educacional e destaca que "empregar o termo tradutor para designar estes profissionais pode ampliar a sua atuação para além da interação face a face, ou seja, para além da mediação no tempo da enunciação, pode também modificar o tipo de formação deste profissional, como prérequisito para atuação na escola".

Com base na diferenciação entre tradução e interpretação, apresentada acima, e nas demandas do campo da educação, é possível falar em intérpretes educacionais e em tradutores educacionais. Entretanto, ao contrário do que muitos textos apresentam, é importante que se entenda que tradutores e intérpretes possuem funções bem distintas no âmbito da educação. Nesse sentido, com base em nossas investigações, podemos elencar as seguintes vertentes de atuação desses profissionais. ${ }^{4}$

\footnotetext{
${ }^{4}$ Não registramos uma atividade bem comum nos contextos educacionais: o processo por meio do qual textos escritos por surdos em português, com forte influência da estrutura da Libras, são "traduzidos", "interpretados" ou "revisados" para que os falantes de português os compreendam sem dificuldades. Consideramos que são necessárias pesquisas capazes de estudar esse processo realizado por tradutores e intérpretes de Libras-Português e, inclusive, de conceituá-lo e categorizá-lo, mostrando de que maneira ele se aproxima ou não de processos de revisão, de tradução ou de interpretação intralinguísticos ou, até mesmo, se corresponderia a outro processo.
} 


\section{Quadro 01 - Tradução e Interpretação em Contextos Educacionais}

\begin{tabular}{|c|c|}
\hline TRADUÇÃO INTERMODAL & INTERPRETAÇÃO INTERMODAL \\
\hline Português-Libras & Português-Libras \\
\hline $\begin{array}{l}\text { - materiais didáticos (livros didáticos e paradidáticos etc.); } \\
\text { - cartilhas e/ou programas escolares; } \\
\text { - literatura dos mais diversos tipos; } \\
\text { - hino nacional e outros; } \\
\text { - sites, blogs e congêneres; } \\
\text { - vídeos educativos diversos; } \\
\text { - vídeos institucionais; } \\
\text { - filmes ou trechos de filmes usados como recurso didático; } \\
\text { - documentários ou partes deles, assim como outras produções } \\
\text { veiculadas na mídia; } \\
\text { - apresentações televisivas: reportagens e telejornais usados como } \\
\text { materiais de apoio à aula; } \\
\text { - documentos jurídicos e institucionais (normas, orientações, } \\
\text { regimentos, estatutos etc.); } \\
\text { - avaliações e atividades diversas; } \\
\text { - provas de concursos, vestibulares e exames nacionais; } \\
\text { - comunicados e informes; } \\
\text { - edição e revisão de traduções. }\end{array}$ & $\begin{array}{l}\text { - interações diversas (aulas ministradas em português, reuniões, } \\
\text { orientações, bancas e demais ações envolvendo os atores da } \\
\text { educação); } \\
\text { - diálogos entre surdos falantes de Libras e ouvintes não fluentes } \\
\text { em Libras; } \\
\text { - materiais e recursos empregados nas aulas: } \\
\text { - livros didáticos e paradidáticos; } \\
\text { - literatura dos mais diversos tipos; } \\
\text { - vídeos educativos diversos; } \\
\text { - sites, blogs e congêneres; } \\
\text { - filmes ou trechos de filmes usados como recurso didático; } \\
\text { - documentários ou partes deles; } \\
\text { - apresentações televisivas: reportagens, telejornais etc. } \\
\text { - hino nacional e outros; } \\
\text { - documentos jurídicos e institucionais (normas, orientações, } \\
\text { regimentos, estatutos etc.); } \\
\text { - avaliações e atividades diversas; } \\
\text { - provas de concursos, vestibulares e exames nacionais; } \\
\text { - bilhetes, mensagens, comunicados e informes. }\end{array}$ \\
\hline Libras-Portu & Libras-Português \\
\hline $\begin{array}{l}\text { - trabalhos dos alunos e atividades diversas; } \\
\text { - produções acadêmicas (artigos, dissertações, teses etc.); } \\
\text { - vídeo-aulas; } \\
\text { - literatura em Libras, incluindo as piadas e os pequenos contos; } \\
\text { - edição e revisão de traduções. }\end{array}$ & $\begin{array}{l}\text { - interações diversas (aulas ministradas em Libras, reuniões, } \\
\text { orientações, bancas e demais ações envolvendo os atores da } \\
\text { educação); } \\
\text { - diálogos entre surdos falantes de Libras e ouvintes não fluentes } \\
\text { em Libras; } \\
\text { - trabalhos dos alunos e atividades diversas; } \\
\text { - materiais e recursos empregados nas aulas; } \\
\text { - literatura em Libras, incluindo as piadas e os pequenos contos. }\end{array}$ \\
\hline
\end{tabular}

Fonte: os autores

Observamos que há diferentes atividades requeridas em contextos educacionais e que o caráter do texto fonte; a condição de realização do trabalho e o registro do produto, por exemplo, indicarão se se trata de um processo de tradução ou de interpretação.

Nos contextos educacionais, a necessidade da interpretação de/para língua de sinais é bem maior que a de tradução. Entretanto, diversas 
interpretações poderiam ser dispensadas se os profissionais, professores e intérpretes, contassem com materiais, recursos, literatura, documentos e avaliações, por exemplo, disponíveis em língua de sinais, ou seja, previamente traduzidos (Santos, 2013).

Por fim, tanto a tradução quanto a interpretação têm o seu lugar e a sua função nesses contextos. Assim, é importante que se reflita sobre o perfil necessário aos tradutores e aos intérpretes de língua de sinais e que se avalie se é viável e possível que um único profissional assuma as duas funções, considerando-se sua formação e as condições de trabalho adequadas ao desempenho de cada uma das atividades.

\subsection{Contextos de saúde}

É comum vermos os intérpretes de língua de sinais definindo os contextos de saúde como sendo somente os consultórios médicos ou as recepções de instituições de saúde. Entretanto, é importante que se considere que contextos de saúde compreendem todo e qualquer espaço estruturado para responder às necessidades de saúde da população. Nesse sentido, todos os ambientes que de alguma maneira englobam as políticas, as rotinas, as práticas de atenção, de prevenção, de recuperação, de reabilitação e de promoção da saúde podem ser tratados como contextos de saúde.

É evidente que a definição de saúde não é algo simples nem trivial, já que pode ser compreendida como "um estado de completo bem-estar físico, mental e social, e não apenas a ausência de doença ou enfermidade" (OMS, 1946). Vale mencionar também que “a atual legislação brasileira amplia o conceito de saúde, considerando-a um resultado de vários fatores determinantes e condicionantes, como alimentação, moradia, saneamento básico, meio ambiente, trabalho, renda, educação, transporte, lazer, acesso a bens e serviços essenciais" (Brasil. Ministério da Saúde, 2005, p. 212).

Podemos assim, entender que esses contextos compreendem (i) o sistema único de saúde e demais instituições que oferecem serviços voltados à saúde da população; (ii) os órgãos governamentais que visam as políticas de 
atenção, prevenção, recuperação, reabilitação e promoção da saúde; (iii) as instituições não governamentais e demais entidades com foco na saúde; (iv) as entidades que lidam com aspectos relacionados à assistência da população no que tange o bem-estar; (v) os espaços formativos de profissionais da área da saúde, dentre outros.

Portanto, o tradutor ou o intérprete de língua de sinais pode atuar numa diversidade de âmbitos que envolvem as áreas do conhecimento relacionadas à saúde: medicina, biomedicina, enfermagem, odontologia, fisioterapia, fonoaudiologia, farmácia, terapia ocupacional, nutrição, educação física, saúde coletiva, análises clínicas, análises de sistema e de serviços de saúde etc. Não podemos deixar de mencionar que os cursos de graduação das Ciências da Saúde são contextos educacionais que se caracterizam também pelos conteúdos e conhecimentos caros à área da saúde. Nesse sentido, há certa interseção de espaços de atuação de tradutores e intérpretes de língua de sinais: "contextos de educação e ensino da saúde".

A despeito da diversidade de contextos de saúde, é comum vermos o profissional que atua nesses espaços sendo nomeado apenas como intérprete médico (medical interpreter). Todavia, encontramos no cenário internacional outros termos, tais como intérprete de saúde ou de cuidados da saúde (healthcare interpreter) e intérprete de hospital (hospital interpreter) (Queiroz, 2011; Jesus, 2013), os quais podem, de certa maneira, ampliar um pouco mais a concepção de quem é o profissional que atua nesses contextos.

No Brasil, não temos uma atuação reconhecida e visível de intérpretes de língua de sinais no âmbitos da saúde nem o estabelecimento de uma formação específica para que esses profissionais tornem-se tradutores ou intérpretes na área da saúde, ainda que haja uma disciplina específica voltada a esse contexto em alguns cursos de graduação, como, por exemplo, (i) a disciplina denominada Laboratório II, no Bacharelado em Letras Libras presencial da Universidade Federal de Santa Catarina (UFSC); (ii) a de Tradução e Interpretação na Esfera da Saúde, no Bacharelado em Tradução e Interpretação em Língua Brasileira de Sinais/ Língua Portuguesa da 
Universidade Federal de São Carlos (UFSCar); e (iii) a de Interpretação Médica, no Letras Libras: Bacharelado em Tradução e Interpretação na Universidade Federal do Espírito Santo (UFES).

Além disso, são raros os casos de contratação de intérpretes de língua de sinais para atuar em hospitais ou outras instituições de saúde no país 5 , como ocorre no contexto estadunidense (Queiroz, 2011). A maioria dos profissionais que atuam como intérpretes de língua sinais em contextos de saúde é ad hoc, ou seja, não possui uma formação ou treinamento específicos e não está diretamente vinculada à instituição que solicita a prestação de serviço.

É interessante notar que encontramos várias referências à atuação de tradutores médicos (medical translators), também conhecidos como tradutores de saúde (healthcare translators), os quais trabalham, basicamente, com textos escritos, não sendo responsáveis por acompanhar ou auxiliar o público em ambientes de saúde (NCIHC, 2010, p.3ss). Essa distinção entre a função dos tradutores e dos intérpretes é destacada pelo National Council on Interpretation in Health Care - NCIHC, em português "Conselho Nacional de Interpretação em Saúde" dos Estados Unidos, e assinala certa afirmação de dois profissionais distintos.

Interpretação e tradução, como é de se esperar, são mais parecidas que diferentes uma da outra. Entretanto, [...] existem diferenças cujo reconhecimento é importante para assegurar a precisão tanto na comunicação oral quanto nos materiais traduzidos por escrito. Uma compreensão clara do conjunto de habilidades, formação e treinamento, assim como a experiência de intérpretes e tradutores deve ser combinada com uma compreensão clara do produto final. $\mathrm{Na}$ interpretação, isso envolve o oferecimento oral de comunicação falada ou sinalizada de uma língua para outra. $\mathrm{Na}$ tradução, isso é a conversão de um texto escrito de uma língua para outra. (NCIHC, 2010, p.16, tradução nossa). ${ }^{6}$

\footnotetext{
${ }^{5}$ Em nossos levantamentos detectamos a contratação de intérpretes de Libras-Português para atuar em hospitais desde 2008, como é o caso do Hospital Estadual Mário Covas de Santo André e, mais recentemente, do Hospital das Clínicas de São Paulo.

6 "Interpreting and translation, not surprisingly, are more common than different from one another. However, $[\ldots]$ there are differences that are important to recognize to ensure the accuracy of both oral communication and written translated materials. A clear understanding of the skill sets, education and training, and
} 
Considerando isso, podemos afirmar que os tradutores de saúde e os intérpretes de saúde que atuam de/para a língua de sinais possuem distintas demandas de trabalho, como elencado no quadro abaixo com base em nossos estudos e investigações.

\section{Quadro 02 - Tradução e Interpretação em Contextos de Saúde}

\begin{tabular}{|c|c|}
\hline TRADUÇÃO INTERMODAL & INTERPRETAÇÃO INTERMODAL \\
\hline Português-Libras & Português-Libras \\
\hline $\begin{array}{l}\text { - livros, enciclopédias, guias e similares; } \\
\text { - artigos de jornais e revistas da área da saúde; } \\
\text { - materiais de conscientização e orientação (folhetos, panfletos, } \\
\text { etc.); } \\
\text { - instruções para procedimentos médicos; } \\
\text { - bulas de medicamentos; } \\
\text { - campanhas de saúde veiculadas na mídia; } \\
\text { - sites e blogs relacionados à saúde; } \\
\text { - formulários diversos (de consentimento, de coletas de dados } \\
\text { etc); } \\
\text { - questionários e testes; } \\
\text { - documentos gerais; } \\
\text { - edição e revisão de traduções. }\end{array}$ & $\begin{array}{l}\text { - interações diversas (triagem, consultas, exames, cirurgias, } \\
\text { boletins médicos, altas, orientações, instruções e demais ações } \\
\text { envolvendo os participantes dos contextos de saúde); } \\
\text { - diálogos entre surdos falantes de Libras e ouvintes não fluentes } \\
\text { em Libras; } \\
\text { - situações envolvendo o serviço de atendimento médico de } \\
\text { urgência; } \\
\text { - receitas e atestados médicos; } \\
\text { - bulas de medicamentos; } \\
\text { - formulários diversos (de consentimento, de coletas de dados } \\
\text { etc); } \\
\text { - questionários e testes; } \\
\text { - materiais de conscientização e orientação (folhetos, panfletos, } \\
\text { etc.) } \\
\text { - campanhas de saúde veiculadas na mídia; } \\
\text { - excertos de livros, enciclopédias, guias e similares; } \\
\text { - trechos de artigos de jornais e revistas da área da saúde; } \\
\text { - documentos gerais. }\end{array}$ \\
\hline Libras-Português & Libras-Português \\
\hline $\begin{array}{l}\text { - trabalhos de alunos e similares; } \\
\text { - produções acadêmicas; } \\
\text { - vídeos com temas da área da saúde; } \\
\text { - relatos de surdos sobre experiências no campo da saúde; } \\
\text { - edição e revisão de traduções. }\end{array}$ & $\begin{array}{l}\text { - interações diversas (triagem, consultas, exames, cirurgias, } \\
\text { boletins médicos, altas, orientações, instruções e demais ações } \\
\text { envolvendo os participantes dos contextos de saúde); } \\
\text { - diálogos entre surdos falantes de Libras e ouvintes não fluentes } \\
\text { em Libras; } \\
\text { - situações envolvendo o serviço de atendimento médico de } \\
\text { urgência. }\end{array}$ \\
\hline
\end{tabular}

Fonte: os autores

experience of interpreters and translators must be matched with a clear understanding of the end product. In interpreting, this involves the oral rendition of spoken or signed communication from one language into another. In translation, this is the conversion of a written text from one language into a different language". 
Assim como observamos nos espaços educacionais, os contextos de saúde possuem diferentes demandas tradutórias e interpretativas. Além disso, é importante que se reflita sobre o perfil de cada um desses profissionais e que se avalie se é viável e possível que um único profissional realize tanto a tradução quanto a interpretação. Dito de outro modo, se o profissional possui os conhecimentos e as habilidades requeridas por cada uma das distintas atividades.

É importante mencionar que, diferentemente dos contextos educacionais que costumeiramente têm uma demanda mais efetiva e contínua por serviços de interpretação, os contextos de saúde possuem uma demanda menos intensa e, em alguns espaços, esporádica. Frente à sua significativa demanda, os ambientes educacionais vêm considerando viável a contratação de profissionais intérpretes de língua de sinais como parte de seu quadro de funcionários. Entretanto, os âmbitos de saúde, com sua demanda menos intensa, não têm contratado intérpretes como parte de seu quadro, salvo raras exceções, mas utilizado profissionais ad hoc. Portanto, é importante que haja centros de interpretação/tradução vinculados ao governo, por exemplo, capazes de oferecer serviços de interpretação remota ou presencial, conforme a demanda.

Por outro lado, é importante considerar que, para as demandas tradutórias, têm sido contratados profissionais e empresas encarregadas de realizar trabalhos pontuais voltados às esferas específicas de saúde.

\subsection{Contextos jurídicos}

Antes de abordamos a tradução e a interpretação de línguas de sinais em contextos jurídicos, é importante que se mencione que o exercício da cidadania de diversas comunidades por meio da garantia de direitos linguísticos é uma discussão recente no campo das Ciências Jurídicas. Encarar a língua como um direito que deve pautar as relações sociais e jurídicas altera não apenas a concepção sobre a língua e seus falantes, mas também a maneira por meio da 
qual essa nova concepção pode impactar e direcionar os operadores do direito (Rodrigues \& Beer, 2016, Beer, 2016).

Outro aspecto interessante refere-se aos caminhos por meio dos quais a tradução e a interpretação de línguas orais e a de línguas de sinais chegaram até o Judiciário brasileiro, os quais são significativamente diferentes. No caso das línguas orais, consideradas idiomas estrangeiros, o Decreto №. 13.609/1943 reconhece e estabelece o ofício do tradutor público e intérprete comercial, já que o português é a língua oficial do país. Em relação às línguas de sinais, em um primeiro momento, as discussões e os encaminhamentos que justificavam a interpretação de/para as línguas de sinais pautavam-se pela visão da surdez como deficiência e, por sua vez, pela garantia de acessibilidade às pessoas surdas.

Rodrigues \& Beer (2016) apresentaram uma discussão relevante em relação à noção de direitos humanos linguísticos e seus impactos, por exemplo, na educação de surdos. Numa abordagem semelhante, mas sob a perspectiva das Ciências Jurídicas, Beer (2016) tece uma reflexão sobre a língua como direito. A autora demonstra que o reconhecimento da língua como direito é um aspecto que deveria ser central, já que a privação linguística pode impedir que o indivíduo usufrua dos demais direitos fundamentais. Assim, modificando a noção de que a língua de sinais seria apenas um mecanismo de acessibilidade das comunidades surdas, Beer (2016) demonstra que a concepção da língua como direito, já observada no ordenamento jurídico brasileiro, é central às políticas linguísticas. Essas reflexões postas no campo das Ciências Jurídicas trazem diferentes implicações, inclusive para a atuação de tradutores e intérpretes de línguas de sinais.

No que se refere ao tradutor e ao intérprete em contextos jurídicos, é importante mencionar que a ideia de que esses profissionais atuam apenas em situações de julgamento ou em tribunais é um mito e, portanto, não procede. A atuação destes profissionais é bastante abrangente no meio jurídico, conforme demonstrado em seguida. Fato que nos faz reafirmar a necessidade de mais pesquisas e de programas de formação e treinamento que capacitem os 
tradutores e intérpretes de línguas de sinais a atuar em consonância com as demandas e exigências de cada espaço e setor.

Vale mencionar que os tradutores e intérpretes de língua de sinais que atuam em atividades formativas ou em cursos oferecidos pelo campo das Ciências Jurídicas encontram-se na interseção de distintos âmbitos, ou seja, vivenciam a articulação da educação com o direito. Considerando que essas atividades e cursos caracterizam-se como espaços educacionais que têm como foco os saberes específicos das Ciências Jurídicas, é possível afirmar que o trabalho desses profissionais se efetiva, também, em "contextos de educação jurídica".

Outro aspecto importante diz respeito às áreas de conhecimento que têm hospedado as pesquisas relacionadas à formação desses profissionais em contextos jurídicos, já que observamos suas afiliações a distintos campos disciplinares. Algumas das pesquisas sobre tradução e interpretação em contextos jurídicos afiliam-se ao campo dos Estudos da Tradução e aos da Interpretação, ao passo que outras investigações estão no âmbito da Linguística Forense. Talvez isso explique as diversas nomeações atribuídas ao profissional que atua com a tradução e/ou a interpretação em contextos jurídicos: tradutor forense, intérprete forense, tradutor público e intérprete comercial, tradutor juramentado, dentre outras.

No Brasil, a produção acadêmica e a oferta de trabalho para tradutores e para intérpretes de línguas de sinais nos contextos jurídicos têm aumentado significativamente nos últimos anos. Com relação às produções acadêmicas neste campo, até agora a maioria delas aborda a complexidade da terminologia jurídica como principal barreira à atuação desses profissionais (Santos, 2016). Sem dúvida, esse tema é de suma importância, mas existem outras questões que também precisam ser tratadas: as relações de poder estabelecidas nos contextos jurídicos no que diz respeito ao tradutor e/ou intérprete; a qualificação e a certificação desses profissionais para atuarem nesses espaços; as variações e/ou os idioletos presentes nas comunidades surdas que acessam a esfera jurídica; e assim por diante. Além disso, pesquisas e produções capazes 
de pensar um programa de formação para esses profissionais são fundamentais, já que constituem um dos primeiros passos para institucionalizar os serviços de tradução e interpretação como parte integrante da esfera jurídica.

Dentre essas pesquisas, encontramos, em relação à formação de profissionais tradutores e intérpretes de línguas orais para os espaços jurídicos, a proposta de Fröhlich (2014), a qual sugere três módulos com "algumas disciplinas para a formação de tradutores forenses", sendo que o total seria de 300 horas para essa formação. Assim teríamos: Módulo 01 - disciplinas de “teorias da tradução, técnicas de tradução e revisão, técnicas de interpretação forense, ateliê do tradutor, competência instrumental"; Módulo 02 disciplinas de "tradução forense, sistemas jurídicos, linguísticos e sociedade, prática tradutória e dinâmica judicial e introdução ao Direito para tradutores"; e Módulo 03 - disciplina de terminologia forense e dinâmica judicial in loco (Fröhlich, 2014, p. 285).

Em âmbito internacional, observamos algumas pesquisas que tratam especificamente da interpretação de/para línguas de sinais em contextos jurídicos (Russel, 2002; Mathers, 2006; Russel \& Hale, 2008). Entretanto, é importante dizer que não vimos referências à atuação de tradutores de línguas de sinais nesses espaços.

Outro ponto importante é que algumas iniciativas para melhor estruturação e operacionalização dos trabalhos que envolvem a tradução e a interpretação de língua de sinais nos contextos jurídicos já foram institucionalizadas nos Estados Unidos (Mathers, 2006). Uma das mais conhecidas e disseminadas é o documento publicado em 2009 pelo National Consortium of Interpreter Education Centers, em português "Consórcio Nacional de Centros de Formação de Intérpretes", que elenca um conjunto das melhores práticas que poderiam ser empregadas por intérpretes de línguas de sinais em ambientes jurídicos.

No referido documento, intitulado Best Practices: American Sign Language and English Interpretation within Court and Legal Settings, em português 
“Melhores Práticas: Interpretação em Língua de Sinais Americana e Inglês em Tribunais e Contextos Legais", há uma série de recomendações e protocolos a serem observados pelos intérpretes de língua de sinais que atuam nesses espaços (Stewart, Witter-Merithew \& Cobb, 2009). Este documento contribui para a profissionalização de tradutores e de intérpretes intermodais não somente dos Estados Unidos, mas também em outros países. Um exemplo disso é o caso do Reino Unido, já que a ASLI - Association of Sign Language Interpreters, em português "Associação de Intérpretes de Língua de Sinais", com base no documento mencionado anteriormente, produziu um novo documento e passou a adotá-lo e recomendá-lo aos intérpretes de Língua de Sinais Britânica (BSL) - Inglês (Best Practices for BSL/English Interpreters Working in Legal Settings).

No Brasil, um fator prejudicial aos tradutores e intérpretes de línguas de sinais nos contextos jurídicos é a escassez de cursos de formação específica ou ainda a ausência de documentos norteadores da atuação nesses espaços. Embora não suficientes, algumas noções introdutórias à atuação deste profissional podem ser encontradas, por exemplo, em disciplinas de cursos de formação de tradutores e intérpretes de línguas de sinais. Dentre essas disciplinas, podemos citar: (i) Laboratório de Interpretação III, no curso de Bacharelado em Letras-Libras presencial (UFSC); (ii) Tradução e Interpretação nas Esferas Legal e Governamental, no Bacharelado em Tradução e Interpretação em Língua Brasileira de Sinais/ Língua Portuguesa (UFSCar); e (iii) Tradução e Interpretação Jurídica, no Letras Libras: Bacharelado em Tradução e Interpretação (UFES).

Vale esclarecer que esses profissionais poderão enfrentar diversas situações de tradução ou de interpretação em audiências, julgamentos, juizados, delegacias, conciliações, consulta a advogados, ministério público, casamentos etc. (Rodrigues, 2010). Não basta apenas compreender os protocolos exigidos para atuação nesses espaços, mas é necessário identificar as demandas e a maneira como distintos contextos situacionais forçam certas escolhas e decisões. Por exemplo, o modo de interpretação (consecutivo, 
intermitente ou simultâneo) que será adotado em uma tomada de depoimento de testemunhas em um julgamento pode ser diferente daquele utilizado quando um cliente surdo procura consultoria jurídica. Raramente, encontramse respaldo ou diretrizes na legislação brasileira vigente que possam orientar a atuação dos tradutores e intérpretes de línguas de sinais em contextos jurídicos. A profissionalização nesse âmbito é bastante incipiente, não contando com orientações sobre como serão certificados esses profissionais, com delimitações acerca de sua contratação, com uma descrição das funções que lhes serão atribuídas, ou ainda com definições de seu local de lotação. Santos (2016, p. 122) afirma

\begin{abstract}
se por um lado o Judiciário brasileiro não está preparado para atender as demandas da língua de sinais, dentre elas, a interpretação e a tradução, por outro lado há carência na formação dos intérpretes de Libras-Português na esfera jurídica. A atual realidade brasileira conta com pouquíssimos intérpretes de Libras-Português especialistas em determinadas áreas, sendo a formação específica na esfera jurídica uma das mais raras.
\end{abstract}

Diante da escassez de formação para esses profissionais, a contratação ad hoc tem ocorrido com frequência, devido, principalmente, ao aumento de sua demanda nos espaços jurídicos. Essa contratação ad hoc pode ocorrer a partir de uma consulta do Judiciário aos bancos públicos de Corregedorias Gerais da Justiça, onde consta um cadastro de peritos, intérpretes e tradutores.

Santos (2016) ressalta que, embora esteja previsto no artigo 192 do Código de Processo Penal a presença de intérpretes de língua de sinais, ela está respaldada para interrogatórios em que a pessoa surda (no texto original "surdo-mudo") não saiba ler ou escrever. No decreto nº. 13.609/1943, que define e regulamenta o ofício de Tradutor Público e Intérprete Comercial, a presença de tradutores e de intérpretes está garantida somente para as línguas orais estrangeiras, ficando descobertas todas as demais línguas que não se enquadram nessa categoria (línguas indígenas e línguas de sinais, por exemplo). 
Considerando as discussões apresentadas sobre a atuação de tradutores e de intérpretes de línguas de sinais nos contextos jurídicos e nossas investigações, elencamos no quadro abaixo algumas possibilidades desses serviços. Embora pareça óbvio, cabe ressaltar que compete ao tradutor ou ao intérprete dedicar-se exclusivamente à sua atividade e não se responsabilizar por atividades relacionadas à execução de ação jurídica ou pericial, ou quaisquer outras que não são do âmbito da tradução e da interpretação, já que tais ações são executadas pelas autoridades competentes.

\section{Quadro 03 - Tradução e Interpretação em Contextos Jurídicos}

\begin{tabular}{|c|c|}
\hline TRADUÇÃO INTERMODAL & INTERPRETAÇÃO INTERMODAL \\
\hline Português-Libras & Português-Libras \\
\hline $\begin{array}{l}\text { - livros, orientações e similares; } \\
\text { - documentos gerais (constituição, leis, decretos, resoluções, } \\
\text { portarias, normativas, contratos e outros); } \\
\text { - formulários diversos (para solicitação de passaportes ou } \\
\text { certidões, para ficha criminal etc.); } \\
\text { - cartilhas, artigos de jornais e revistas da área; } \\
\text { - materiais de conscientização e orientação (folhetos, panfletos, } \\
\text { etc.); } \\
\text { - campanhas da área veiculadas na mídia; } \\
\text { - glossários e dicionários; } \\
\text { - sites institucionais e congêneres; } \\
\text { - edição e revisão de tradução. }\end{array}$ & $\begin{array}{l}\text { - interações diversas (audiências, julgamentos, acareações, } \\
\text { depoimentos e demais ações envolvendo os participantes dos } \\
\text { contextos jurídicos); } \\
\text { - diálogos entre surdos falantes de Libras e ouvintes não fluentes } \\
\text { em Libras; } \\
\text { - situações envolvendo as polícias: } \\
\text { - emissão e renovação de passaporte, porte de armas e } \\
\text { similares; } \\
\text { - atendimentos a ocorrências gerais (acidentes de trânsito, } \\
\quad \text { violência doméstica, agressões etc.); } \\
\text { - boletins de ocorrência, atestado de antecedentes criminais, } \\
\quad \text { inquérito policial etc.; } \\
\text { - situações de exames diversos (corpo de delito, perícias de áudio } \\
\text { e imagem, perícias de crime contra o patrimônio e outros); } \\
\text { - serviços junto ao Instituto Médico Legal (em casos que figure } \\
\text { pessoas surdas falantes da língua de sinais); } \\
\text { - programas televisivos veiculando situações da esfera jurídica; } \\
\text { - partes ou excertos de materiais diversos e formulários que } \\
\text { circulam nos contextos jurídicos; } \\
\text { - excertos cartilhas, artigos de jornais e revistas da área; } \\
\text { - materiais de conscientização e orientação (folhetos, panfletos, } \\
\text { etc.); } \\
\text { - campanhas da área veiculadas na mídia. }\end{array}$ \\
\hline Libras-Português & Libras-Português \\
\hline $\begin{array}{l}\text { - trabalhos de estudantes, cursistas e similares; } \\
\text { - produções acadêmicas; }\end{array}$ & $\begin{array}{l}\text { - interações diversas (audiências, julgamentos, acareações, } \\
\text { depoimentos e demais ações envolvendo os participantes dos }\end{array}$ \\
\hline
\end{tabular}


- documentários, campanhas etc.;

- análise ou avaliação de traduções;

- edição e revisão de traduções. contextos jurídicos);

- diálogos entre surdos falantes de Libras e ouvintes não fluentes em Libras;

- situações envolvendo a presença de falantes de Libras como usuários dos serviços oferecidos pelos diferentes contextos jurídicos.

Fonte: os autores

Como podemos observar no quadro acima, os contextos jurídicos apresentam diversas demandas interpretativas. Muitas dessas demandas já são conhecidas e, inclusive, têm sido atendidas por intérpretes ad hoc de língua de sinais. Por outro lado, a tradução de língua de sinais no contexto jurídico, embora não venha sendo efetivamente realizada, é uma possibilidade de se ampliar o acesso das pessoas surdas aos conhecimentos e às informações veiculadas, prioritariamente, em ambientes jurídicos.

É importante que as comunidades reconheçam seus direitos linguísticos e apresentem suas demandas aos operadores do direito. Assim, poderão exigir, não somente a acessibilidade aos serviços oferecidos nos contextos jurídicos, mas, principalmente, favorecer e intensificar a constituição de um novo olhar capaz de fomentar a consolidação de políticas linguísticas que contemplem o uso de suas línguas no âmbito jurídico por meio da tradução e da interpretação realizadas por profissionais devidamente qualificados.

\section{Considerações Finais}

Os contextos de serviços públicos, embora seja um campo comum da interpretação comunitária, não excluem a interpretação de conferências nem mesmo a tradução. É interessante notar que, ainda que esses espaços sejam marcados por um caráter intrassocial, eles se caracterizam pela complexidade das áreas em que se localizam. Os serviços disponíveis em diferentes âmbitos educacionais, jurídicos e de saúde vinculam-se a uma série de aspectos sociais, culturais, econômicos, tecnológicos, científicos e políticos que conferem às diferentes demandas por interpretação e por tradução de/para língua de sinais 
características singulares que variam de contexto para contexto, de situação para situação e de cliente para cliente.

Outro fator importante à compreensão dos serviços de tradução e de interpretação demandados nos três contextos discutidos neste texto é a diferenciação entre os processos tradutórios e os interpretativos e, por sua vez, a especificidade desses processos quando realizados entre uma língua de modalidade gestual-visual e outra vocal-auditiva. Além disso, a tradução para a língua de sinais, muitas vezes, realiza-se por meio de seu registro em vídeo com base na performance visual do tradutor e não apenas em um sistema de escrita da língua de sinais. Essa particularidade traz implicações à operacionalização do processo tradutório intermodal e exige do profissional conhecimentos e habilidades específicas.

Portanto, considerando (i) a diferença entre os processos tradutórios e interpretativos; (ii) a singularidade da tradução e da interpretação intermodais; (iii) a ampliação da demanda por tradução e por interpretação de/para línguas de sinais em espaços educacionais, jurídicos e de saúde; (iv) a multiplicidade das situações que ocorrem em cada um dos âmbitos abordados; e (v) as distintas demandas por interpretação comunitária e por interpretação de conferência nesses contextos, concluímos que a formação dos profissionais tradutores e/ou intérpretes de línguas de sinais é o aspecto central para a qualidade do serviço prestado por esses profissionais.

Entretanto, é importante dizer que devido à grande variabilidade das demandas que se apresentam aos tradutores e aos intérpretes de línguas de sinais, tanto dentro de um mesmo âmbito (aquelas de caráter intracontextual) quanto nas interseções entre âmbitos distintos (aquelas de caráter intercontextual), há que se refletir sobre as possibilidades da formação de um profissional generalista em contraposição à necessidade da formação de especialistas. Nesse sentido, é indispensável, a priori, que se leve em conta nessa reflexão a distinção entre o trabalho de tradutores e o de intérpretes, o caráter singular de cada espaço em que esses profissionais podem atuar, assim como suas diversas demandas intracontextuais. 
Enfim, esperamos que as reflexões apresentadas possam contribuir para a compreensão da tradução e da interpretação de/para línguas de sinais em diferentes contextos de serviços públicos e também incentivar novas pesquisas capazes de contribuir para a compreensão dos múltiplos espaços em que o tradutor e o intérprete de língua de sinais podem atuar, bem como com o conhecimento das diferentes demandas tradutórias e interpretativas das variadas situações em que cada uma dessas atividades se realiza.

\section{Agradecimentos}

Gostaríamos de registrar nossos agradecimentos às valiosas contribuições de Hanna Beer, Paulo Paz da Silva, Neiva Albres, Vânia Santiago, Ringo Bez de Jesus e Renato Guimarães, as quais foram importantíssimas às reflexões apresentadas neste texto.

\section{Referências}

ALBRES, N. A. Intérprete educacional: políticas e práticas em sala de aula inclusiva. São Paulo: Harmonia, 2015.

BEER, H. Direitos linguísticos como direitos fundamentais: as políticas linguísticas para as comunidades surdas no ordenamento jurídico brasileiro. TCC (Trabalho de Conclusão de Curso) - Faculdade de Direito, Universidade Federal de Juiz de Fora, Minas Gerais, 2016. Disponível em: <https://repositorio.ufjf.br/jspui/handle/ufjf/3768> Acesso em: 12 abr. 2017.

BRASIL. Decreto $\mathbf{n}^{\mathbf{0}} \mathbf{5 . 6 2 6}$, de 22 de dezembro de 2005. Regulamenta a Lei no 10.436, de 24 de abril de 2002, que dispõe sobre a Língua Brasileira de Sinais Libras, e o art. 18 da Lei no 10.098, de 19 de dezembro de 2000. Diário Oficial da União, República Federativa do Brasil, Atos do Poder Executivo, Brasília, DF, 23 dez. 2005, nº 246, ano CXLII, Seção 1, p. 28-30.

BRASIL. Lei no 12.319, de 01 de setembro de 2010. Dispõe sobre a regulamentação da profissão de Tradutor e Intérprete da Língua Brasileira de Sinais - Libras. Diário Oficial da União, República Federativa do Brasil, Atos 
do Poder Legislativo, Brasília, DF, 2 set. 2010. № 169, ano CXXXIX, Seção 1, p. 43.

BRASIL. MINISTÉRIO DA SAÚDE. O SUS de A a Z: garantindo saúde nos municípios. Brasília, DF: Ministério da Saúde, 2005.

BRITO, L. F. Por uma gramática de língua de sinais. Rio de Janeiro: Tempo Brasileiro, 1995.

CAVALLO, P.; REUILLARD, P. Estudos da Interpretação: tendências atuais da pesquisa brasileira. Letras \& Letras, [S.1.], v. 32, n. 1, p. 353-368, ago. 2016. Disponível em:

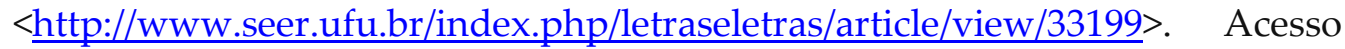
em: 12 fev. 2017.

FROHLICH, L. R. Tradução forense: um estudo de cartas rogatórias e suas implicações. 2014. Tese (Doutorado em Estudos da Tradução) - Programa de Pós-Graduação em Estudos da Tradução, Universidade Federal de Santa Catarina, Florianópolis, $2014 . \quad$ Disponível em: $<$ https://repositorio.ufsc.br/xmlui/handle/123456789/128797>Acesso em: 21 abr. 2017.

GILE, D. Conference and simultaneous interpreting. In: BAKER, M. (Org.) Routledge Encyclopedia of Translation Studies. Londres e Nova York: Routledge, 1998. p.40-45.

Translation Research versus Interpreting Research: Kinship, Differences and Prospects of Partnership. In: SCHÄFFNER, C. (ed.) Translation Research and Interpreting Research: Traditions, Gaps and Synergies. Clevedon, Buffalo and Toronto: Multilingual Matters, 2004. p. 10-34.

GOHN, M. G. Educação não-formal, participação da sociedade civil e estruturas colegiadas nas escolas. Ensaio: aval. pol. públ. Educ., Rio de Janeiro, v.14, n.50, p. 27-38, jan./mar. 2006.

ISHAM, W. P. Signed language interpreting. In: BAKER, M. (org.) Routledge encyclopedia of translation studies. London; New York: Routledge, 1998. JESUS, R. B. A Interpretação Médica para Surdos: a atuação de intérpretes de LIBRAS/Português em contextos da saúde. 2013. Trabalho de Conclusão de 
Curso (TCC). Graduação. Universidade Federal de Santa Catarina, Florianópolis, 2013. Disponível em: <https://repositorio.ufsc.br/handle/123456789/105420> Acesso em 10 ago. 2016. KLIMA, E.; BELLUGI, U. The Signs of Language. Cambridge: Harward University Press, 1979.

LIBÂNEO, J. C. Pedagogia e pedagogos, para quê? 9 ed. São Paulo: Cortez, 2007.

MATHERS, C. Sign language interpreters in court: Understanding best practices. Bloomington, Indiana: Author House, 2006.

MEIER, R. P. Why different, why the same? Explaining effects and non-effects of modality upon linguistic structure in sign and speech. In: MEIER, R. P; CORMIER, K.; QUINTO-POZOS, D. Modality and structure in signed and spoken languages. Cambridge: Cambridge University Press, 2004. p.1-25.

NCIHC. ATA. NHELP. What's in a Word? A Guide to Understanding Interpreting and Translation in Health Care, National Health Law Program, 2010. OMS. Constituição da Organização Mundial da Saúde (OMS/WHO), 1946.

PADDEN, C. A. Simultaneous Interpreting across modalities. Interpreting. n.5, v.2, 2000/01, p.169-185.

PAGURA, R. A interpretação de conferências no Brasil: história de sua prática profissional e a formação de intérpretes brasileiros. 2010. Tese (Doutorado em Estudos Linguísticos e Literários em Inglês) - Faculdade de Filosofia, Letras e Ciências Humanas, Universidade de São Paulo, São Paulo, 2010. Acesso em: 12 abr. 2017 Disponível em $<$ http://www.teses.usp.br/teses/disponiveis/8/8147/tde-09022011-151705/ptbr.php> Acesso em 10 abr. 2015.

. A Interpretação de Conferências: interfaces com a tradução escrita e implicações para a formação de intérpretes e tradutores. DELTA, v.19, esp. 2003. p.209-236. Disponível em: $<$ http://www.scielo.br/pdf/delta/v19nspe/13.pdf $>$. Acesso em: 02 Jun. 2015. 
. Tradução \& Interpretação. In: AMORIM, L. M.; RODRIGUES, C. C.;

STUPIELLO, E. N. A. Tradução \&: perspectivas teóricas e práticas. São Paulo: Unesp Digital, 2015. p.183-207

PÖCHHACKER, F. Introducing interpreting studies. London: Routledge, 2004 .

QUADROS, R. M.; KARNOPP, L. B. Língua de Sinais Brasileira: estudos linguísticos. Porto Alegre: ARTMED, 2004.

QUADROS, R. M.; SOUZA, S. X. Aspectos da tradução/ encenação na Língua de Sinais Brasileira para um ambiente virtual de ensino: práticas tradutórias do curso de Letras-Libras. In: QUADROS, R. M. de. (Org.). Estudos Surdos III. Petrópolis, Rio de Janeiro: Arara-Azul, 2008: 168-207.

QUADROS, R. SEGALA, R. Tradução intermodal, intersemiótica e interlinguística de textos escritos em Português para a Libras oral. Cadernos de Tradução, Florianópolis, v. 35, n. 2, 2015, p. 354-386. Disponível em: $<$ https://periodicos.ufsc.br/index.php/traducao/article/view/2175-

7968.2015v35nesp2p354>. Acesso em: 12 abr. 2017

QUEIROZ, M. Interpretação médica no Brasil. 2011. Dissertação (Mestrado em Estudos da Tradução) - Centro de Comunicação e Expressão. Universidade Federal de Santa Catarina, Florianópolis, 2011. Disponível em: $<$ https://repositorio.ufsc.br/handle/123456789/95825> Acesso em 10 nov. 2016 RODRIGUES, C. H. A interpretação para a Língua de Sinais Brasileira: efeitos de modalidade e processos inferenciais. 2013. Tese (Doutorado em Linguística Aplicada) - Faculdade de Letras, Universidade Federal de Minas Gerais, Minas Gerais, 2013. Disponível em: $<$ http://hdl.handle.net/1843/MGSS9CXQ8L> Acesso em: 06 abr. 2016.

- Da interpretação comunitária à interpretação de conferência: Desafios para formação de intérpretes de língua de sinais. In: Congresso Nacional de Pesquisa em Tradução e Interpretação de Língua de Sinais Brasileira, II, 2010, Florianópolis. Anais... Florianópolis: Universidade Federal de Santa Catarina, 2010. Disponível em: 
<http://www.congressotils.com.br/anais/anais2010/Carlos $\% 20 H e n r i q u e \% 20$ Ro drigues.pdf $>$ Acesso em: 10 nov. 2016.

RODRIGUES, C. H.; BEER, H. Direitos, Políticas e Línguas: divergências e convergências na/da/para educação de surdos. Educação e Realidade, v. 41, 2016, p. 661-680. Disponível em:

$<$ http://www.seer.ufrgs.br/index.php/educacaoerealidade/article/view/61114>. Acesso em 10 Jan. 2017.

RODRIGUES, C. H.; SILVÉRIO, C. C. P. Interpretando na educação: quais conhecimentos e habilidades o intérprete educacional deve possuir? Revista Espaço, Rio de Janeiro, v. 35, 2011, p. 42-50.

RUSSELL, D. Interpreting in legal contexts: Consecutive and simultaneous interpretation. Burtonsville, MD: Linstock Press, 2002.

RUSSELL, D.; HALE, S. Interpreting in legal settings. Washington, D.C.: Gallaudet University Press, 2008.

SANTOS, S. A. Contextualização dos Estudos da Interpretação no Brasil. In: QUADROS, R. M; STUMPF, M. R.; LEITE, T. A. (Org.). Estudos da Língua Brasileira de Sinais I. Florianópolis: Insular, 2013, v. 1, p. 119-152.

- Questões emergentes sobre a interpretação de libras-português na esfera jurídica. Revista Belas Infiéis, v. 5, n. 1, p. 117-129, 2016. Disponível em: $<$ http://periodicos.unb.br/index.php/belasinfieis/article/view/19511> Acesso em: 30 jan. 2017.

STEWART, K; WITTER-MERITHEW, A; COBB, M. Best Practices American Sign Language and English Interpretation Within Legal Settings. National Consortium of Interpreter Education Centers, Estados Unidos, 2009. p.1-50.

WADENSJÖ, C. Community Interpreting. In: BAKER, M. (org.) Routledge Encyclopedia of Translation Studies. Londres e Nova York: Routledge, 1998. p.33-37.

WURM, S. Translation across Modalities: The Practice of Translating Written Text into Recorded Signed Language. An Ethnographic Case Study. 2010. PhD Thesis (Doctor of Philosophy) - Heriot-Watt University, Department of Languages and Intercultural Studies. 2010. 


\title{
Resumo
}

Os múltiplos contextos em que ocorrem a interpretação e a tradução de/para línguas de sinais trazem à tona a importância de se refletir sobre questões que envolvem a atuação de intérpretes e tradutores intermodais. Partindo da diferenciação entre tradução e interpretação, assim como da caracterização de alguns contextos, discutimos a atuação desses profissionais em serviços públicos educacionais, jurídicos e de saúde. Por fim, destacamos a importância de se considerar: (i) a singularidade dos processos intermodais; (ii) a complexidade dos contextos e de suas demandas; e (iii) a centralidade da formação.

Palavras-chave: Línguas de sinais; tradução intermodal; serviços públicos; interpretação comunitária; tradução.

\begin{abstract}
The several settings in which interpreting and translation from/into sign languages take place bring to light the importance of reflecting on issues involving the work of intermodal interpreters and translators. Considering the difference between translation and interpreting, as well as the characterization of some settings, we discuss the work of these professionals in education, legal and healthcare public services. In conclusion, we emphasize the importance of taking into account: (i) the singularity of intermodal processes; (ii) the complexity of settings and their requirements and (iii) the centrality of training. Keywords: Sign language; intermodal translation; public service; community interpreting; translation.
\end{abstract}

